\title{
Rutherford and Daresbury labs to merge as 'self-standing institution'
}

London. Britain's largest academic-support laboratory, the Rutherford Appleton Laboratory (RAL), with a budget of $£ 58$ million a year, will in future be financed directly by the Office of Science and Technology.

At the same time, RAL will be merged with the Daresbury Laboratory, best known for its synchrotron radiation source, to which British and many other research groups have access.

Both laboratories have hitherto been run by the Science and Engineering Research Council (SERC). RAL is near Didcot in Oxfordshire; Daresbury is 150 miles north in Cheshire. Under the new arrangement, the merged laboratory will have "selfstanding" status under the Office of Public Service and Science.

The move, announced last week by science minister William Waldegrave, forms part of the reorganization of the research councils proposed by the government in a white paper (policy document) in May, and in particular the division of the SERC into an Engineering and Physical Sciences Research Council (EPSRC) and a Particle Physics and Astronomy Research Council (PPARC).

Both laboratories started as spin-offs from the government's interest after the Second World War in nuclear energy, and at first focused on nuclear research. They have since evolved into multidisciplinary centres housing large research equipment and facilities used by university scientists from Britain and abroad.

Rutherford - at which Britain's early particle accelerators were built - now operates the spallation neutron source ISIS, and several other major engineering and supercomputer facilities. Daresbury hopes to persuade the government to back plans for a new international synchrotron radiation facility, following premature closure of its Nuclear Structure Facility earlier this year (see Nature 362, 278; 1993).

One proposal made during discussions leading up to the white paper was that each laboratory should be attached to one of the new research councils. But Waldegrave has accepted the view of Sir David Phillips, chairman of the Advisory Board for the Research Councils, that this would be impractical because the laboratories are multidisciplinary.

Under the new arrangements, a single director based at Rutherford would be responsible for both institutions (a description of Daresbury in Phillips's draft conclusions as an "outpost" of Rutherford has been dropped in the final version of his advice to Waldegrave). The laboratories will share a common management and a joint mission statement. This will outline what services they are expected to provide the research councils, but also allow them to bid for research and service contracts from other public and private organizations.

Staff at the laboratories have generally welcomed the government's decision to let the new organization stand on its own. "The shorter management chain will mean we will be able to make our activities leaner, cleaner and more effective," says Alan Leadbetter, director of Daresbury.

Some are concerned, however, that their new status might be a first step towards privatization - a fate that is being considered for all public laboratories following publication of the white paper, and an accompanying report prepared by the government's efficiency adviser Sir Peter Levene and its chief scientific adviser Bill Stewart.

Staff would strongly resist any such move as inappropriate because the institutions depend heavily on public funds. "We are very concerned about the possibility of privatization, since we do not feel that either institution could be run on a profit basis," says Tony Bell of the Institute of Professionals, Managers and Specialists, the

\section{Aspirin on trial as HIV treatment}

Washington. An $\$ 88,000$ clinical trial at a New York hospital is to test whether aspirin is useful in treating HIV infection.

The nonprofit Community Research Initiative on AIDS will fund the trial: no public money is involved. Dr Donald Kotler of St Luke's-Roosevelt Hospital Center will lead it. Beginning in August, he will treat 46 asymptomatic HIV-infected volunteers for eight weeks with either aspirin or a placebo; the aspirin dose of four grams a day is similar to that commonly used to treat severe arthritis.

Kotler, who has worked with people suffering from AIDS in New York since the epidemic began a decade ago, says he has test-tube evidence that salicylates - a class of compounds of which aspirin is the best known - can inhibit HIV. He is ready for some ridicule over the use of the world's most famous catch-all medicine in the trial, but says: "I'm more concerned that some people might read about this and start popping aspirins." As for peer scepticism, he says: "I'm not sure who is in a position to start throwing stones."

Dr David Ho, director of the Aaron Diamond AIDS Research Center in New York, union that represents scientific staff at the two laboratories.

Senior laboratory officials say that, apart from a proposal that the new organization could eventually be turned into an independent not-for-profit company, full privatization has not been seriously discussed: it would for example create many practical difficulties over ownership of research equipment.

Leadbetter also dismisses concerns that the laboratories will be more vulnerable to future budget cuts now that they have no research council to protect them. "Look at what happened [to the Nuclear Structure Facility] under the old system," he says. "But we are worried about the prospects of reduced research budgets, tighter management, and the government's greater willingness to close public bodies than in the past."

Waldegrave also announced last week that he had accepted Phillips's proposals to transfer most SERC-funded bioengineering research to the new Biotechnology and Biological Sciences Research Council, and not to the EPSRC as the SERC had hoped (see Nature 364, 272; 1993).

David Dickson

will help to assess the outcome of the study, without necessarily endorsing Kotler's hypothesis. "I don't know much about the protocol," he says. "I know a little bit about Kotler's rationale and he has some preliminary data. This is an easy thing to do and is the right type of project for a community-based organization. Mainstream researchers are going to be sceptical, but if he has some data it should be tested out."

Kotler thinks that HIV pathogenesis involves a vicious circle of inflammation and infection in the intestine that treatment by salicylates might break. He has gathered in vitro and in vivo data to support his theory, but says he has not attracted the funding to produce as much "hard data" as he would like.

Some of the more promising data have involved salicylates other than aspirin. But he will use aspirin because if such a cheap therapy worked it would offer hope to so many people. No-one, least of all Kotler, is touting aspirin as the next wonder-cure for AIDS: the best hope is that it will buy some patients a little more time.

Colin Macilwain 